\title{
LIBERTAD POSITIVA Y CAPACIDAD POLÍTICA EN DEMOCRACIA A PARTIR DEL ENFOQUE DE CAPACIDAD DE AMARTYA SEN
}

\author{
ROSARIO CARVAJAL \\ Universidad de Cádiz
}

\begin{abstract}
RESUMEN: Este texto parte del enfoque de capacidad de Sen, referido a facetas de la libertad de la que disponen los individuos para alcanzar sus objetivos, y que requiere de oportunidades sustantivas que remiten a la libertad positiva. Estas libertades asociadas a las diferentes facetas de capacidad de Amartya Sen sirven para determinar los elementos que constituyen el término de capacidad política. Se distinguen dos dimensiones en la democracia: la democracia como proceso y la democracia como resultado. Las libertades políticas tienen su centro en la democracia como proceso, referidas a la participación ciudadana en los asuntos públicos. La otra dimensión se refiere a la democracia como resultado de políticas públicas y sus efectos sobre la población. Ambas dimensiones de la democracia afectan a las capacidades o libertades políticas de los ciudadanos. Las capacidades políticas, como libertades de individuos y grupos, son posibles si la democracia ofrece oportunidades de satisfacción de necesidades y de participación política. De acuerdo a esta aproximación de capacidad política, una democracia que reduce las oportunidades y limita las vías de participación pública de la ciudadanía, está limitando sus libertades políticas, pero también otras libertades fundamentales de la ciudadanía.
\end{abstract}

PALABRAS CLAVE: libertad positiva, capacidades (libertades), funcionamientos, oportunidades, razonamiento público, democracia, Amartya Sen, Isaiah Berlin.

\section{Positive Liberty and Political Capability in Democracy from the Capability Approach of Amartya Sen}

\begin{abstract}
: this text deal with the approach of the capability, identified with the facets of freedom of individuals to reach goals, and that have necessity of substantive opportunities as result of a bigger liberty, the positive liberty. The freedom facets of Amartya Sen are used to determine the elements to constitute the political capability term. The paper distinguishes two dimensions of democracy: democracy as process and democracy as result. The political freedom has its centre into the democracy as process, with repect to the citizenship participation in public issues. The another dimension refers to the democracy as result concerning policies and its effects on the population. Both dimensions affect to the political capabilities of the citizenship. The political capabilities, as freedom of individuals and groups, are possible if the democracy offers opportunities to satisfy necessities and political participations. According to this approach of political capacibility, if a democracy reduces opportunities and restricts the ways of public participation by citizens, then it is restricting the political capabilities (freedom), and even this limitations shorten others fundamental liberties of the citizens.
\end{abstract}

KEY WORDS: positive liberty, capabilities (freedoms) functionings, opportunities, public reasoning, democracy, Amartya Sen, Isaiah Berlin.

\section{INTRODUCCIÓN}

La libertad puede ser abordada, a grandes rasgos, desde un nivel macro, a partir de la referencia a la libertad positiva y a la libertad negativa (Berlin, 2004), o desde un nivel micro, correspondiente a los espacios de libertad de los 
que pueden hacer uso los individuos, en relación al enfoque de capacidad de Sen. El presente trabajo centra el interés en el enfoque de capacidad (libertad individual), pero resaltando la perspectiva macro de la libertad positiva en la obra de Sen. Esta libertad positiva remite a cuestiones de quién ejerce la libertad y con qué criterios, y qué condiciones la favorecen.

Para la libertad positiva la ausencia de algo puede hacer a una persona no libre (Badillo, 1991: 69), y enlaza con el enfoque de la capacidad, pues la capacidad equivale a la libertad de la que puede disponer una persona si cuenta con las oportunidades sustantivas (Sen, 2010: 51). Sen enfatiza la importancia de la libertad positiva, de modo que la ausencia de oportunidades sería un atentado a la libertad o capacidad de los individuos para llegar a lograr lo que ellos valoran para sus vidas. Algunos de estos espacios de libertad que resultan de la presencia de libertad positiva contribuyen al bienestar de la persona (capacidad de bienestar). Otras libertades facilitan la autorrealización del individuo, la participación en su toma de decisiones (capacidad de agencia, capacidad de poder o libertad de proceso), o el control de los medios (capacidad de control), destacadas aquí al delimitar el término de capacidad política.

El enfoque de capacidad de Sen se utiliza como referente teórico para hacer una propuesta de qué entender por capacidad política. En este caso, el término capacidad política remite justamente a las facetas de libertad antes mencionadas, pero situándolas distintivamente en dos dimensiones de la democracia, la democracia como proceso y la democracia como resultado. La democracia como proceso comprende libertades políticas de participación ciudadana y comunicación entre representantes y representados. En la democracia como resultado la libertad se valora en base a los criterios que marcan la redistribución de los recursos disponibles entre la población (de sanidad, educación, justicia, seguridad social, impuestos, entre otros), y que tiene su reflejo en la satisfacción de necesidades básicas para los individuos.

Por otro lado, también se hacen algunas observaciones relacionando la libertad positiva y el enfoque de capacidad con una democracia representativa en sentido tradicional, frente a una democracia con elementos más deliberativos. Reflexionando sobre estas cuestiones se puntualiza el interés del razonamiento público, de la responsabilidad de las instituciones, y del uso adecuado de los medios de comunicación y de las nuevas tecnologías que sirven para propiciar debates que contribuyan a ampliar las libertades de la ciudadanía.

\section{LIBERTAD POSITIVA}

La definición de qué es la libertad positiva pasa primeramente por determinar qué es la libertad negativa. Berlin (2004: 364) define la libertad negativa en respuesta a la pregunta qué dificulta o limita la libertad, y esta libertad se da en ausencia de la interferencia de otros, queda limitada, por tanto, por la intromisión de obstáculos hechos por el hombre, tanto de forma deliberada como no 
intencionada. Por otro lado, la libertad positiva remite a la cuestión de cómo soy gobernado, si por delegación de otros o por uno mismo, y qué justifica y facilita el modo en el que soy gobernado (Berlin, 2004: 365). Para Carter (2010: 17), la libertad negativa queda definida según el grado en el que los individuos o grupos sufren la interferencia externa de otros, en cambio, la libertad positiva está determinada por factores internos que afectan al grado en que los individuos o grupos actúan de manera autónoma. El enfoque de capacidad de Sen tiene en cuenta tanto los factores internos como externos que condicionan o promueven las libertades de los individuos. Sen (1997: 132) delimita la libertad negativa cuando se da inmunidad de interferencia, y tiene un papel instrumental en la promoción de la libertad positiva. Pero es justamente el aspecto de la libertad positiva el que cobra mayor atención en los escritos de Sen, dándole unas connotaciones de significación diferentes a la definición que da Berlin. Para Berlín (Sen, 1997: 131-132) la libertad positiva se determina en términos más reducidos, en particular en lo que respecta a superar los obstáculos que provienen de dentro de la persona ${ }^{1}$, mientras que para Sen la libertad positiva la conforman tanto los factores internos como los externos, porque ambos son determinantes para la autonomía de acción de los individuos (Álvarez, 2012; Sen, 2002). En líneas generales, en el enfoque de capacidad de Sen la libertad negativa remite a los factores que dificultan el ejercicio de la libertad, en tanto la libertad positiva indica los elementos que hacen posible ejercitar la libertad.

La libertad positiva trata de la cuestión de quién gobierna nuestras vidas, lo que implica reflexionar sobre la libertad de acción, incluida la toma de decisiones. Estas libertades de acción contribuyen, en alguna medida, a la autogestión de la persona. En este sentido, en el ámbito político la libertad positiva en la democracia representativa implica una libertad por delegación de los individuos a los representantes, porque son estos los que están legitimados para tomar decisiones que contribuyan a mejorar las libertades individuales de la ciudadanía. Según Berlin (2004: 366), siguiendo a Platón, una élite política de los mejores, los más sabios, son los que disponen de la capacidad para elegir las opciones más racionales para su pueblo, en este caso la libertad política está asegurada si el pueblo se gobierna por los mejores. Pero esta perspectiva de la libertad positiva por delegación, además de partir de una concepción particular del individuo, lleva a una noción estrecha de que solo hay una respuesta verdadera, la que dan los expertos (Berlin, 2004: 367). Justamente Guizot (2001: 291) ya definía la libertad política del hombre como el triunfo de la razón del representante sobre las pasiones humanas del pueblo. Bajo este mismo razonamiento, para Sieyes (1950: 117) el parlamento, como asamblea que simboliza la democracia representativa, se convierte en el instrumento de racionalidad sobre el que se apoya la racionalidad de sus parlamentarios/as.

\footnotetext{
1 Esta limitación del autogobierno por factores internos se reconoce ya en Kant, para quien «el hombre libre no necesita del reconocimiento público para tener libertad, (...), su condición noumenal permanece intacta y es enteramente libre y humana al margen de cómo se le trate» (BERLIN, 2004: 240).
} 
Si la libertad positiva, en la democracia representativa, se asienta en una visión indirecta de la libertad política de los individuos delegada a los representantes como expertos, en la democracia deliberativa se empodera a la ciudadanía para que adopte una actitud activa y responsable hacia la política, haciéndola partícipe en los procesos de toma de decisiones. Esta percepción más rica del individuo va pareja al reconocimiento de identidades sociales, y en coherencia con esto se rechaza que a la persona se la «clasifique como miembro de una amalgama deforme, como una unidad estadística sin atributos propios, y se aboga entonces por un agente responsable de sus propias vidas» (Berlín, 2004: 239). En palabras de Berlín (2004: 252): «El pluralismo es un ideal más verdadero y más humano que los fines de aquellos que buscan en las grandes estructuras disciplinarias, es más verdadero porque reconoce que los fines humanos son múltiples, en parte inconmensurables y en permanente conflicto». Sen también reconoce esta diversidad humana como un hecho ineludible, pero no se queda en el permanente conflicto a que da lugar la multiplicidad social de Berlin, sino que propone hacer de esta diversidad una oportunidad para el enriquecimiento humano mediante la discusión o razonamiento público (Sen, 2010). Este reconocimiento a la diversidad, frente al concepto de libertad positiva por delegación asentada en el experto de la democracia representativa, es también el reconocimiento de que existen diferentes perspectivas u opiniones y que, por tanto, las razones son también múltiples².

Justamente, esta insistencia en la ineludible presencia de la diversidad social explica por qué la libertad positiva en el enfoque de capacidad es un aspecto esencial de la libertad que tiene que ver con las oportunidades sustantivas que den respuestas a las diversas necesidades presentes en una sociedad heterogénea (Sen 2010: 317). Y es que sin estas oportunidades sustantivas difícilmente la persona puede llegar a lograr las cosas que considera importantes para su vida. En la tradición racionalista iniciada por Kant los fines racionales son los únicos que pueden ser objetos verdaderos de la naturaleza verdadera de un hombre libre (Berlín, 2004: 237). Pero para Sen (2010: 79) los logros que los individuos quieren para sus vidas son los que consideran más valiosos, y pueden corresponder tanto a metas racionales como sentimentales. En este sentido, Sen se distancia de Kant y mantiene más similitudes con Hume. Si bien el ejercicio de la razón es central también en Sen, lo es fundamentalmente considerando la diversidad social, las diferentes posiciones y valoraciones de los individuos.

Se vuelve a insistir que en su enfoque de capacidad se aprecia especialmente el énfasis que pone en las oportunidades como elementos vitales en la relación entre libertad y democracia, remitiendo a una cuestión principal de la libertad positiva: ¿qué necesito para ejercer mi libertad? Desde una perspectiva estrictamente liberal de la economía clásica, un claro ejemplo es el pensamiento neoliberal, lo que se necesita para ampliar la libertad de los individuos es ampliar los márgenes de la libertad negativa, de la no intromisión del otro,

2 No se entra aquí en un no reconocimiento de esta diversidad, en una valoración ética de lo que supone un concepto unívoco de la racionalidad. 
con la intención de dejar hacer a la sociedad y al mercado (laissez faire). Sen, ante esta pregunta de qué necesito para ejercer mi libertad acentúa el interés de los medios como elemento esencial que hacen posible la capacidad de oportunidad, de modo que el ejercicio de la libertad individual no sólo requiere de la no intromisión del otro (libertad negativa), sino también de la intervención del otro (del gobierno o de instituciones concretas) facilitando los recursos para que los individuos ejerciten su libertad. Vista la libertad positiva desde esta perspectiva, el sentido democrático fundamentado en principios éticos de solidaridad cobraría un giro renovado y necesario.

\section{Libertad y ENFoque de CAPACIDAD DE SEN}

Tal como se está insistiendo, un contexto favorable a la libertad positiva favorece el desarrollo de las capacidades, cuyo fin último sería proporcionar más autonomía a los individuos. Antes se vio cómo Berlin se interesaba en su obra por demarcar qué entender por libertad al distinguir entre libertad positiva y libertad negativa, pero en sentido amplio. En cambio, Sen da un paso más al establecer varias facetas de libertad individual a nivel micro. En esta sección se enumeran y definen algunas de estas facetas de libertad o capacidades. Se parte de la base que «capacidad es el poder de hacer algo, la responsabilidad que emana de esa habilidad, de ese poder, es una parte de la perspectiva de la capacidad» (Sen, 2010: 51), de modo que la libertad contribuya al autogobierno del individuo. Robeyns (2005: 95) anota que «la distinción entre los funcionamientos logrados y las capacidades esta entre lo realizado y lo efectivamente posible, en otras palabras, entre logros, por un lado, y libertades u opciones valorables a partir de las cuales uno puede elegir, por la otra», por lo que habría que distinguir entre la libertad (capacidad) de la que dispone un individuo y los logros que es capaz de alcanzar con esa libertad. En sus aspectos sustantivos el enfoque de capacidad trata sobre las posibilidades de elecciones y consecución de logros de las personas, lo que la gente quiere hacer y se esfuerza por ser y hacer en contextos específicos.

No es tarea fácil dar una definición precisa del enfoque de capacidad. Alkire (2002: 10) justifica esta falta de claridad bajo el supuesto de que Sen pone más atención en criticar ciertos aspectos de la economía (utilitarismo) que en clarificar su enfoque de capacidad. Por su parte, Cejudo (2006: 368) sostiene que, a pesar de la importancia de su enfoque, la exposición de Sen no es especialmente clara ${ }^{3}$. En líneas generales, en su definición de capacidad distingue varias facetas de libertad distribuidas entre capacidad de bienestar y capacidades

\footnotetext{
3 Por otro lado, Toвoso y Arnau (2008: 72) creen que podrían distinguirse tres niveles sobre el término capacidad: 1) capacidad para lograr efectivamente algo; 2) capacidad para funcionar, y 3) conjunto de capacidad, que es el formado por todos los funcionamientos de los que es capaz la persona (también en CEJUDO, 2006: 368), incluyendo tanto funcionamientos como capacidades.
} 
de acción que recogen la tabla 1. Pero también reconoce la existencia de los factores de conversión que facilitan o dificultan los funcionamientos que hace posible el paso de capacidades o libertades a realizaciones.

\section{TABLA 1.}

ENFOQUE DE CAPACIDAD Y SUS ELEMENTOS

\begin{tabular}{|c|c|c|c|}
\hline $\begin{array}{l}\text { Capacidades } \\
\text { (libertades) }\end{array}$ & Oportunidades & $\begin{array}{l}\text { Funcionamientos } \\
\text { (logros) }\end{array}$ & $\begin{array}{l}\text { Factores de } \\
\text { conversión (de } \\
\text { oportunidades a } \\
\text { funcionamientos) }\end{array}$ \\
\hline $\begin{array}{l}\text { Capacidad de } \\
\text { Bienestar }\end{array}$ & $\begin{array}{l}\text { Oportunidades de } \\
\text { bienestar }\end{array}$ & $\begin{array}{l}\text { Funcionamientos } \\
\text { de bienestar }\end{array}$ & \multirow{2}{*}{$\begin{array}{l}\text { Personal, social, } \\
\text { cultural y } \\
\text { medioambiental }\end{array}$} \\
\hline $\begin{array}{l}\text { Capacidad de } \\
\text { Acción: } \\
\text { a) Capacidad de } \\
\text { proceso } \\
\text { b) Capacidad de } \\
\text { control } \\
\text { c) Capacidad de } \\
\text { agencia }\end{array}$ & $\begin{array}{l}\text { Oportunidades de } \\
\text { poder } \\
\text { Oportunidades de } \\
\text { control }\end{array}$ & $\begin{array}{l}\text { Funcionamientos } \\
\text { de proceso } \\
\text { Funcionamientos } \\
\text { de agencia } \\
\text { Funcionamientos } \\
\text { de control }\end{array}$ & \\
\hline
\end{tabular}

Elaboración propia.

Robeyns (2005: 99) menciona los factores de conversión basados en lo personal, social y medioambiental que dificultan o reducen la conversión que hagan las personas de sus capacidades (del uso de su libertad a partir de unas oportunidades) a funcionamientos (logros). Los factores de conversión influyen en los individuos y hacen que el enfoque de la capacidad se estudie siempre dentro de un contexto, que afecta a la habilidad para alcanzar funcionamientos. Nos apoyamos sobre las evaluaciones de los individuos, pero estas valoraciones son resultado de la interacción profunda entre ellos y sus contextos (Sen, 2000a; 2010: 275), de manera que hay contextos facilitadores o limitadores de libertad, aunque este texto no profundice en ello y se centre principalmente en las facetas de capacidad o libertad.

Entre las facetas de capacidad, la de bienestar permite a los individuos mejorar su calidad de vida, sin que ésta equivalga siempre a la toma de decisiones. Por ejemplo, ante un accidente en el que el individuo queda inconsciente y necesita de una intervención quirúrgica, la decisión del médico es decisiva para su bienestar, porque en este caso la persona no tiene posibilidad de elegir, de igual modo en muchas situaciones de dependencia por discapacidad. En cambio, las capacidades de acción son ejercidas por individuos activos, porque «estas capacidades son parte del poder efectivo que una persona tiene para optar a las cosas que consideran valiosas para sus vidas» (Sen, 2010: 301). Estas libertades requieren, para que sean efectivas, de espacios de oportunidad mediante los cuales los individuos llegan a ser más autónomos, como personas 
activas y responsables de sus actos. Las facetas de capacidad de acción pueden llevarle a preferencias que no tienen que ver con el bienestar, como por ejemplo actos de generosidad frente a otros que implican sacrificio propio. Se hace referencia con estas libertades de acción a las capacidades de agencia, proceso y control. Pero antes se necesita de la capacidad de oportunidad como libertad fundamental. De hecho, Sen (1997: 128) enfatiza que la libertad tiene, al menos, las capacidades de oportunidad y de proceso como las más importantes.

Precisamente, la capacidad de proceso se refiere a la libertad de decisión de las personas (Sen, 1997: 32), del poder de elegir, y se identifica con la condición de ser agente o sujeto activo. En la capacidad de proceso se acentúa la faceta de libertad de toma de decisiones de forma autónoma y sin interferencia de otros (Sen, 1997: 132, 2010: 256 y 335). Va unida a la capacidad de oportunidad, referida a la existencia de oportunidades reales que permiten a los individuos elegir las cosas que ellos valoran como buenas para su vida (Sen, 1997: 128, 2002: 520). En este sentido, Álvarez (2012: 79) sostiene que la capacidad de oportunidad se equipara a la capacidad de poder por cuanto hace posible la consecución de los logros. El hecho de «ser capaz de elegir» un funcionamiento entre otros es factible porque hay oportunidades para elegir. En esta línea, la presencia de opciones permite a la persona decidir usarlas o no. Es importante esta diferencia entre tener o no tener oportunidades (recursos o medios), si bien el hecho de disponer de oportunidades no significa que todos los individuos hagan uso de ellas. Como Sen (2010: 265) sostiene: «el centro del enfoque de capacidad no está sólo en lo que la gente de hecho hace, sino también lo que uno tiene posibilidad de hacer, de elegir o no elegir entre las opciones disponibles» y que nuevamente remite a la presencia de libertad positiva.

En cuanto a los logros de agencia, se refieren al éxito de la persona en la búsqueda de la totalidad de sus metas y objetivos (Sen, 1995: 71). Por ejemplo, una persona puede considerar importante para su vida ser un misionero o un reportero de guerra. Estos fines no tendrían como propósito en sí mejorar la calidad de vida de la persona, sino su libertad de agencia (tener la posibilidad de dirigir su vida del modo en el que quiera), lo que le llevaría a los funcionamientos resultantes (ser misionero o reportero). Complementariamente, en la libertad de control (Sen, 1997: 92-93), lo importante es participar en la mediación del proceso a partir del cual los individuos tienen poder para inspeccionar o supervisar algunos mecanismos del proceso de toma de decisiones (Sen, 1997: 96-97) —el ser consciente de cómo funciona el proceso y ser parte del control del proceso- . De este modo, la capacidad de poder (libertad de elegir y la libertad de hacer y ser) puede ampliarse a la libertad o capacidad de control. Estas facetas de libertad se aplican a la actividad política de forma argumentada en la siguiente sección.

Por otro lado, hay que hacer hincapié en dos matizaciones importantes sobre la argumentación teórica del enfoque de capacidad (Gore, 1997; Robeyns, 2005, Deneulin and McGregor, 2010; Sen, 2010). Primeramente, llama la atención que este enfoque se sustenta en una visión pluralista de la libertad, y por otra parte, se refiere principalmente a la libertad del individuo, aunque no se 
trate de individuos aislados, puesto que estos están siempre en relación con los otros (Sen and Dréze, 2002: 6). Es esta relación con los otros la que favorece la capacidad de la que pueda disponer una persona, ya que la libertad, en buena medida, «es un producto de la organización social» (Sen, 1999a: 35), y son justamente las organizaciones o instituciones sociales las que principalmente hacen posible la existencia de oportunidades sustantivas para la libertad de los individuos.

En primer lugar, y como se acaba de describir, su enfoque de capacidad implica el reconocimiento de diversas facetas de libertad, destacando la importancia de la diversidad de situaciones a partir de las cuales las personas llegan a ser y hacer (funcionamientos). De hecho, la heterogeneidad humana es indicativa de que podemos ser iguales en una categoría, pero ser muy desiguales en otras (Sen, 1995: 16). Por ejemplo, que unas personas dispongan de los mismos ingresos económicos viene acompañado de desigualdades en otros ámbitos como puede ser en salud, coste de su vivienda, número de hijos, discapacidad, género, entre otros. La desigualdad en los aspectos mencionados repercute en los espacios de libertad del individuo, ya que las desiguales posiciones sociales en la organización social limitan nuestras capacidades.

En segundo lugar, el enfoque de capacidad se relaciona con el individualismo, en tanto que su unidad de análisis es el individuo, pero sería un error confundirlo con el individualismo metodológico, porque las elecciones y acciones individuales no están separadas de la sociedad, ya que su enfoque está preocupado también por cómo la influencia social afecta a lo que los individuos valoran (Sen, 2010: 274-275). Tan importante es la relación con el otro que la capacidad implica la oportunidad de decidir qué hacer, es el poder de hacer algo, pero viene de la mano de la responsabilidad para con uno mismo y para con los demás, lo que abre el ámbito a las existencias del deber (Sen, 2010: 51; Carvajal, 2015). En otras palabras, la libertad así concebida remite a la relación responsable del individuo con los otros, como muestra la importancia que el autor le da a las políticas sociales y a los debates públicos, tan necesarios para el funcionamiento democrático, como se verá a continuación.

\section{CAPACIDAD POLÍTICA: DEMOCRACIA COMO PROCESO Y DEMOCRACIA COMO RESULTADO}

La propuesta teórica sobre capacidad política que se presenta aquí parte de los espacios de libertad (capacidades) definidos en la sección anterior, y tienen una repercusión directa en la participación activa de la ciudadanía en política. Pero de forma indirecta también afecta a la capacidad política el grado de bienestar conseguido por la ciudadanía, por cuanto estos logros de bienestar favorecen a su vez que la ciudadanía ejerza sus derechos y responsabilidades públicas en los asuntos políticos.

Para delimitar el análisis de la capacidad política se distinguen dos aspectos correspondientes a dos dimensiones de la democracia: la democracia como 
proceso y la democracia como resultado. La democracia como proceso remite a la participación política, a la toma de decisiones durante elecciones, referéndums, participaciones en reuniones, comités, entre otros. Esta dimensión de democracia incluye los espacios de comunicación política entre representantes y representados, comprende los procedimientos de toma de decisiones que existen y los fines que se persiguen (funcionamientos). Por su parte, la democracia como resultado apunta a las políticas públicas y a sus efectos sobre las vidas de las personas (funcionamientos), y comprende también una evaluación de la equidad en la distribución social de recursos. Porque desde la perspectiva de la capacidad resulta importante considerar la evaluación de la equidad en la distribución de las oportunidades (Sen, 2010: 326).

TABLA 2.

CAPACIDAD POLÍTICA EN LAS DOS DIMENSIONES DE LA DEMOCRACIA

\begin{tabular}{|l|l|l|l|l|l|}
\hline \multicolumn{2}{|l|}{ Democracia como proceso } & \multicolumn{2}{l|}{ Democracia como resultado } \\
\hline $\begin{array}{l}\text { Capacidad } \\
\text { de acción }\end{array}$ & Funcionamiento & Oportunidad & Capacidad & Funcionamiento & Oportunidad \\
\hline $\begin{array}{l}\text { Capacidad de } \\
\text { oportunidad } \\
\text { capacidad } \\
\text { de agencia } \\
\text { capacidad } \\
\text { de proceso } \\
\text { capacidad de } \\
\text { control }\end{array}$ & $\begin{array}{l}\text { Logros } \\
\text { alcanzados por } \\
\text { la ciudadanía } \\
\text { en la vida } \\
\text { pública } \\
\text {-ámbito } \\
\text { político- }\end{array}$ & $\begin{array}{l}\text { Medios o } \\
\text { recursos } \\
\text { para la } \\
\text { participación } \\
\text { yel control } \\
\text { político }\end{array}$ & $\begin{array}{l}\text { 1. Capacidad de } \\
\text { oportunidad } \\
\text { Capacidad de } \\
\text { bienestar } \\
\text { Capacidad de } \\
\text { agencia }\end{array}$ & $\begin{array}{l}\text { Logros } \\
\text { alcanzados por } \\
\text { la ciudadanía } \\
\text { para la calidad } \\
\text { de vida y su } \\
\text { desarrollo } \\
\text { personal }\end{array}$ & $\begin{array}{l}\text { Recursos } \\
\text { o medios } \\
\text { para que la } \\
\text { ciudadanía } \\
\text { alcance } \\
\text { calidad de } \\
\text { vida (salud, } \\
\text { educación, } \\
\text { vivienda, } \\
\text { trabajo). }\end{array}$ \\
\hline
\end{tabular}

Elaboración propia.

La tabla 2 recoge las capacidades distribuidas correspondientemente en cada una de las dos dimensiones de democracia: la democracia como proceso y la democracia como resultado. Una de estas capacidades fundamentales, como se comentó anteriormente, remite a la libertad de oportunidad presente en las dos dimensiones de democracia. Además, a nivel práctico son los funcionamientos o logros de la ciudadanía, resultantes de estos espacios de libertad, los más factibles de estudiar empíricamente. De cualquier modo, el paso primero para que se den estos espacios de libertad es que existan las oportunidades o recursos sustantivos, pero antes es necesaria una previa libertad positiva que lo haga possible.

4 Sin embargo, hoy día las políticas públicas penetran no sólo en la capacidad de bienestar, sino también en la capacidad de agencia, porque los gobiernos se dirigen a la responsabilidad de los individuos para que se hagan cargo de su propio bienestar; quede dicho aunque no se profundice en ello en este texto. 
Siguiendo con la democracia de proceso, en esta dimensión pueden establecerse diferentes niveles de capacidad política, según el modelo democrático tienda a un mayor margen de gobierno por delegación (democracia representativa), u ofrezca a la ciudadanía más espacios directos de participación activa (democracia deliberativa). El hecho de que existan más mecanismos de participación política en un determinado contexto democrático permite una mayor libertad de agencia y libertad de proceso. Por ejemplo, en Europa el modelo democrático belga posibilita referéndums a la ciudadanía con una cierta frecuencia para que se posicionen frente a determinadas cuestiones de interés público. Este hecho permite una mayor libertad de proceso (toma de decisiones) entre sus ciudadanos, pero también de agencia, porque la ciudadanía se involucra así en la vida pública de forma activa haciéndoles parte responsable de la actividad política, y por lo tanto, ciudadano activo en el quehacer de la vida pública (capacidad de agencia). En cambio, en otros contextos políticos la libertad de agencia en el ámbito político queda restringida si los individuos no tienen libertad de expresión, de asociación, de reunión, o no disponen de medios de comunicación, ya sea de prensa, televisión, radio o Internet, con libertad para facilitar una información óptima a la ciudadanía.

Un grado importante de libertad política se da también en aquellas democracias que permitan espacios reconocidos de capacidad de control. Esta capacidad de control está referida a la libertad de la persona para ejercer control sobre el proceso de decisión. En los países democráticos los ciudadanos eligen a sus representantes y esperan obtener las oportunidades adecuadas que les permitan logros de bienestar y de agencia, en coherencia con lo que los representantes seleccionados les prometieron en el programa electoral. Los ciudadanos seleccionan a sus representantes políticos mediante el voto electoral (funcionamiento), pero la existencia de elecciones no garantiza la capacidad de control si la ciudadanía no dispone de poder para inspeccionar el mecanismo de elección ni a sus representantes cuando incumplen su programa electoral, por ejemplo. El espacio de libertad de capacidad de control está todavía limitado en muchos países democráticos, y queda un largo camino para mejorar en esta dirección. Justamente, para Cohen (1994: 125) se da libertad débil en ausencia de la libertad de control, observación esta que podría servir para referirse a los diferentes grados de libertad existentes entre democracias. Sin embargo, en las últimas décadas las democracias representativas, principalmente de países occidentales, han aprobado interesantes iniciativas que favorecen la capacidad de control de la ciudadanía. La constatación de leyes de transparencias es una realidad en muchos países europeos, incluida España, y facilita la capacidad de control. Este tipo de iniciativas democráticas se aprecia también en las medidas de gobierno abierto ${ }^{5}$ de diversas instituciones como

5 El gobierno abierto significa a) transparencia en las acciones del gobierno; b) facilitar la participación de la ciudadanía en el diseño e implementación de las políticas públicas; y c) favorecer la generación de espacios de colaboración entre los diversos actores, particularmente entre las administraciones públicas, la sociedad civil y el sector privado (RAmírez AluJA, 2010). 
universidades, en el parlamento, en organizaciones no gubernamentales, por poner solo algunos ejemplos.

En la democracia como resultado el interés se asienta en evaluar el nivel de equidad social que alcanza su organización social en un contexto determinado. En esta dimensión de la democracia cobra un peso importante la capacidad de bienestar, referida a las posibilidades del individuo para lograr calidad de vida. Una democracia de resultado más justa contribuirá a una mayor equidad en la distribución de los recursos entre los diferentes estratos sociales, mientras las democracias con menos eficiencia social constatarán una importante desigualdad en la distribución de medios de sus políticas públicas entre su población (salud pública, sistema educativo, mercado laboral, vivienda, entre otros). Esto tendrá su reflejo en el funcionamiento de las dos dimensiones de la democracia. En este aspecto hay un reconocimiento de que la evaluación favorable de una distribución social justa explica mucho mejor el desarrollo social que otras aproximaciones como ingresos, patrimonio, consumo global, oferta de servicio de salud (Sen, 2010: 326). Desde luego, las dos dimensiones de la democracia, de proceso y de resultado, están interconectadas, porque las desigualdades sociales interfieren seriamente en la participación política, y viceversa, ya que más participación política entre la población mejora la distribución de recursos entre la ciudadanía (Sen y Drèze, 2002: 10).

\section{CAPACIDAD POLÍTICA, GLOBALIZACIÓN Y DISCUSIÓN PÚBLICA}

Si bien son ciertas las interconexiones entre las libertades presentes en las dos dimensiones democráticas, que se retroalimentan mutuamente, Sen enfatiza precisamente la democracia como proceso, vista como un sistema de demandas basado en la discusión pública y la deliberación, más que en una relación mecánica de la política justificada meramente en la elección y el voto (Srinivasan, 2007; Sen, 1999, 2002, 2010). Dentro de lo que puede entenderse como discusión pública, el espacio de Internet, según cómo se utilice, podría favorecer al menos la confrontación de opiniones diversas. Se une el hecho de que la globalización puede facilitar también la discusión pública, afectando a la capacidad política si se amplían las oportunidades de participación política de la ciudadanía, porque la discusión pública para Sen es un instrumento valioso para la consecución de logros de las personas.

La capacidad política de la que disponen los individuos, en cualquier zona geográfica, recibe de alguna u otra manera influencia global de dos frentes: a) por el efecto de Internet y de otros medios de comunicación en general, y

Por tanto, supone una importante transición institucional en la búsqueda de nuevos modelos de gobernanza, y la puesta en marcha de nuevos entramados organizativos y sistema de gestión orientados a fomentar la apertura y una nueva forma de gobernar en el contexto de la sociedad red (Ramírez Aluja, 2012: 15). 
b) por efecto de organizaciones internacionales (Unión Europea, Organización de Nacionales Unidas, Fondo Monetario Internacional, entre otros, pero también de Organizaciones no gubernamentales-ONG-). Ambos frentes afectan a las oportunidades de las que puedan hacer uso los individuos en sus respectivas comunidades. La ciudadanía ve reducidos o ampliados sus espacios de libertad política por estas influencias.

En lo que respecta al uso de Internet, en algunos países árabes este medio fue utilizado para la protesta ciudadana por ciertos sectores de la población que denunciaron las restricciones que sufrían en sus derechos políticos y civiles. Internet podría ser un canal idóneo para la discusión pública. Existen algunos debates en Internet, como en foros, que amplían los encuentros entre personas de contextos diferentes, permitiendo que el debate cuente con una mayor diversidad de opiniones. Pero también hay autores que subrayan sus limitaciones, una de estas voces disidentes es Evgeny Morozov (2011), para quien la sociedad occidental tiende a divulgar mitos sobre las benevolencias de Internet sin cuestionarlas, promoviendo eslóganes que dan por sentado la libertad en la red, o la idea de que cuanta más información, más democracia. $\mathrm{El}$ autor parte de la premisa de que hay que cuestionar críticamente estas ideas preconcebidas, y comprobarlas empíricamente. Según este autor, Internet encierra ante todo demasiada diversidad (cfr. Sádaba, 2014). También la posibilidad de que Internet pueda funcionar como medio para ejercitar las libertades democráticas se pone en entredicho en el trabajo de Rodríguez Prieto y Martínez Cabezudo (2016:116), quienes destacan cómo las empresas privadas ejercen un poder importante en la red, la misma participación en redes sociales conlleva la aceptación de este poder que puede derivar incluso en problemas de seguridad jurídica ${ }^{6}$.

Si no existieran limitaciones a la racionalidad, que puedan venir de medios de comunicación, o de procesos deliberativos complejos por las partes intervinientes, entonces la discusión pública propiciaría las libertades participativas y enriquecería la capacidad política de la ciudadanía. De cualquier modo, y a pesar de estas limitaciones, Sen siempre aboga positivamente por la deliberación pública. Pone el ejemplo del uso de la discusión pública sobre la desigualdad de género en la región de Kerala, en la India, que sirvió para destacar la importancia de libertades participativas no reconocidas antes a las mujeres (Sen, 2010: 272). Esta perspectiva de la utilidad del razonamiento público se rastrea ya en Hume, para quien las acciones racionales se producen como resultado de la propia deliberación sobre las consecuencias y la naturaleza de una determinada línea de conducta por parte del deliberante (Badillo, 19991: 36). También Sen (2010: 203) reconoce a Hume, junto con Adam Smith, en el interés que ambos pusieron en la importancia de las interacciones humanas

\footnotetext{
6 Los autores estudian, entre otras cuestiones, cómo servidores situados en el extranjero, o los abusivos contratos de uso, sitúan Internet en una cierta paralegalidad que puede colisionar con la libertad de expresión.
} 
para debatir entre diversas opiniones como medio para elaborar razonamientos imparciales.

Pero su defensa de los debates públicos no le hace perder de vista que hay elementos que pueden interferir, como muestra su inquietud por cuál es la relación entre la razón y las emociones, incluidas la compasión y la simpatía. Y más allá de estas cuestiones también se pregunta cuál es la última justificación de la confianza en la razón (Sen, 2010: 65). No obstante, a pesar de las limitaciones existentes para la elaboración de razonamientos imparciales, la discusión pública sigue siendo una salida a este estrecho confinamiento individual, siempre que se de la presencia de diversidad de opiniones sobre el tema tratado, favoreciendo así la imparcialidad con la búsqueda de objetividad (Sen, 2010: 203; 74-75). Una discusión pública global, como permiten las nuevas tecnologías (si no existieran graves limitaciones en su uso, como ya se ha dicho), puede ser un medio para superar los límites del parroquianismo de valores al que se refería Smith. El tener en cuenta las opiniones de espectadores imparciales (ajenos a la comunidad de pertenencia) de Adam Smith, introduce perspectivas nuevas a la cultura de la comunidad, de modo que da cabida a nuevos argumentos que pueden ser muy necesarios o pertinentes para ampliar los espacios de libertad (Sen, 2010: 74).

\section{ConcLusiones}

Recapitulando, el enfoque de capacidad de Sen se asienta principalmente en una libertad positiva, que se ejercita cuando existen los medios necesarios (oportunidades sustantivas). Estos medios al alcance de la ciudadanía permiten, a su vez, que puedan ampliarse los espacios de libertad de los individuos. Entre las distintas facetas de capacidad de Sen se han definido las de bienestar, de agencia, de control, de proceso y de oportunidad. Se insiste en la libertad positiva porque de hecho de las dos capacidades que Sen clasifica como fundamentales, la libertad de proceso y la libertad de oportunidad, esta última reitera nuevamente la necesidad de que la persona pueda disponer de oportunidades para perseguir sus metas. La presencia de libertad positiva, bajo esta perspectiva, permite al individuo ejercer su libertad como ser autónomo capaz de llevar un comportamiento activo (alcanzar funcionamientos), de forma responsable frente a otros, y aún a pesar de los factores limitadores a la libertad, como son los personales, sociales, medioambientales.

En cuanto a las capacidades políticas de las que puede hacer uso la ciudadanía en la democracia como proceso cobra un protagonismo central la participación política, la deliberación y la racionalidad pública. La racionalidad en Sen se fundamenta en el razonamiento imparcial, que se consigue tras reflexionar sobre las diversas perspectivas posibles mediante el uso del debate público. Éste es un instrumento muy poderoso en el ejercicio de la capacidad política para la consecución de logros, y se da cuando existen espacios de libertad 
política que permiten la participación y el compromiso activo de la ciudadanía. Asimismo, la globalización (Internet, medios de comunicación, Organizaciones Internacionales, Organizaciones no Gubernamentales) ejercen también una gran importancia contribuyendo a la libertad positiva y a las facetas de la libertad de la ciudadanía, porque abren nuevas posibilidades, oportunidades, recursos de conocimiento o información, favoreciendo la presencia de espacios de participación para el debate político, enriqueciendo la capacidad política de la población al ampliar la libertad positiva.

Ciertamente, la capacidad política se presenta de un modo particular aquí. El texto propone trabajar con el término del enfoque de capacidad de Sen aplicándolo en este caso al ámbito político. Es en la democracia de proceso donde se incluirían determinadas capacidades que cobran más protagonismo, relacionadas con la participación de la ciudadanía en la vida pública, haciéndose referencia a las capacidades de proceso, de agencia, y de control. El hecho de distinguir entre estas libertades políticas en una determinada democracia podría ser un primer paso para calibrar los márgenes de libertad política del individual (capacidades). Estos espacios tienen sus equivalencias también en las posibilidades de las que dispongan la ciudadanía para lograr hacer o ser las cosas que consideran valiosas para su vida personal, evaluables en la dimensión de democracia como resultados. Pero son las libertades políticas en la dimensión de democracia como proceso las que garantizan estos éxitos.

Además, se insiste, partiendo del enfoque de capacidad de Sen, en la responsabilidad compartida entre instituciones, gobierno u organismos competentes de facilitar las oportunidades sustantivas para la libertad de las personas. Pero también de la responsabilidad de la ciudadanía, ejercitando su libertad, de la que se espera un comportamiento activo y comprometido con uno mismo y con los demás.

\section{Bibliografía}

Álvarez YÁGÜEZ, J. (2012), «Amartya Sen. La concepción vigorosa de la libertad». Claves de Razón Práctica, n. 219, pp. 76-82.

AlakiRe, S. (2002), Valuting freedom: Sen's capabiliting approach and povert reduction. Oxford: Oxford University Press.

Badillo O’Farrel, P. (1991), ¿Qué libertad? En torno al concepto de libertad en la acutal filosofía política británica. Madrid: Tecnos.

BERLIN, I. (2004), Sobre la libertad. Madrid: Alianza.

CARTER, I. (2010), «Libertad negativa y positiva». Astrolabio. Revista Internacional de Filosofía, n. 10, pp. 15-35.

Carvajal Muñoz, M. R. (2015), «Identidad social en Amartya Sen: vinculando libertad y responsabilidad en democracia». ARBOR. Ciencia, Pensamiento y Cultura, 269, Vol. 191-775, n. 269.

Cejudo Córdoba, R. (2006), «Desarrollo humano y capacidades. Aplicaciones de la teoría de las capacidades de Amartya Sen a la educación». Revista Española de Pedagogía, n. 234, pp. 365-380. 
Cohen, G. A. (1994), «Amartya Sen’s Unequal World». New left Review, 203, pp. 117-129.

Deneulin, S. and McGregor, J. A. (2010), «The capability approach and the politics of a social conception of wellbeing». European Journal of Social Theory, 13(4), pp. 501-519.

Gore, Ch. (1997), «irreducible social goods and the informational basis of Amartya Sen's capability approach», Journal of International Development, 9(2), pp. 235-350.

Guizot, F. (2001), The history of the origins of the represntative government in Europe. Usa: Liberty Fund (Indiana).

Morozov, E. (2011), El desengaño de Internet: los mitos de la libertad en la red. Barcelona: Destino.

Ramírez-Aluja, Á. V. (2012), «Gobierno abierto es la respuesta: ¿cuál era la pregunta? Más poder local, n. 12, pp. 14-22.

Ramírez-Aluja, Á. V. (2010), «Innovación en la gestión pública y open government (gobierno abierto). Una vieja nueva idea». Revista Buen Gobierno, n. 9, pp. 94-133. Disponible en: http://bit.ly/OqJzUu

Robeyns, I. (2005), «The capability approach: a theoretical survey». Journal of Human Development, 6 (1), pp. 93-114.

Rodriguez Prieto, R. y Martínez Cabezudo, F. (2016), Poder e Internet. Un análisis crítico de la red. Madrid: Cátedra.

Sádaba Rodríguez, I. (2014), «Un paseo por el lado oscuro de la red» (Entrevista con Evgeny Morozov). Minerva, n. 22, pp. 66-71. Disponible en: http://www.revistami nerva.com/articulo.php?id=585

SEN, A. K. (1979), «Equality of what?» The tanner lecture. Stanford University, pp. 195-220.

Sen and Nussbaum, M. (1993), The quality of life. Oxford: Clarendon.

Sen (1995), Nuevo examen de la desigualdad. Madrid: Alianza.

SEN (1997), Bienestar, justicia y mercado. Barcelona: Paidós.

SEN, A. (1999a), La libertad individual como compromiso social. Quito-Ecuador: Ediciones Abuy-Yala.

SEN, A. K. (1999), «Democracy as a Universal Value». Journal of Democracy 10, pp. 3-17.

SEN (2000), Desarrollo como libertad. Madrid: Planeta.

SEN (2000a), «La razón antes que la identidad». Letras Libres, n. 2, pp. 12-18.

SEN y Drèze, J. (2002), India: Development and participation. Oxford: Clarendon Press.

SEN, A. K. (2002), Rationality and Freedom. Massachusetts: Belknap.

SEN, A. K. (2005), «Human rights and capabilities». Journal of Human Development, 6(1), pp. 93-114.

Sen, A. K. (2010), La idea de justicia. Madrid: Taurus.

SkINNER, Q. (2005), «La libertad de las republicas: ¿un tercer concepto de libertad?» Isegoria, 33, pp. 19-49.

SIEYÈs, E. (1950), ¿Qué es el estado llano? Madrid: Instituto de Estudios Político.

SRINIVASAN, S. (2007), «No democracy without justice: Amartya Sen's unfinished business with the capability approach». Journal of Human Development, 8 (3), pp. 457-480.

Toboso Martín, M. y Arnau Ripollés, Mª S. (2008), «La discapacidad dentro del enfoque de capacidad y funcionamientos de Amartya Sen». Araucaria. Revista Iberoamericana de Filosofía, Política y Humanidades, n. 20, pp. 64-94.

Universidad de Cadiz

Ma Rosario Carvajal Muñoz

Departamento de Economía General

rosario.carvajal@uca.es

[Artículo aprobado para publicación en noviembre de 2014] 
